\title{
O ESTRESSE PARA TRABALHADORES DE UMA COOPERATIVA DE SAÚDE: UMA ANÁLISE FENOMENOLÓGICO-EXISTENCIAL ${ }^{1}$
}

\author{
Stress for Workers of a Cooperative Health: an Existential-Phenomenological Analysis \\ El Estrés para los Trabajadores de una Cooperativa de Salud: un Estudio \\ Fenomenológico-Existencial
}

Melck Kelly Piastrelli Mota da Silva

Sylvia Mara Pires de Freitas

\begin{abstract}
Resumo: Este artigo é resultado da pesquisa realizada no curso de Especialização em Saúde Mental e Intervenção Psicológica da Universidade Estadual de Maringá. A pesquisa objetivou investigar e compreender, a partir de entrevistas com os funcionários de uma cooperativa de saúde da cidade de Maringá, como significam e vivenciam o estresse, bem como suas ações diante o mesmo. Foram utilizados como referenciais teóricos e metodológicos: a fenomenologia husserliana e o método fenomenológico, o existencialismo sartriano e o método progressivo-regressivo. A análise apontou que o estresse é compreendido pelos trabalhadores de maneira a-histórica, acrítica e individual. Eles, por um lado, acreditam que fatores externos são responsáveis pela produção do estresse e, contraditoriamente, tomam para si a culpa por não conseguirem superá-lo. Esse entendimento, por sua vez, é corroborado pelas teorias tradicionais hegemônicas sobre estresse e pela indústria da saúde, as quais não alienam somente o conhecimento dos funcionários sobre o assunto, mas também o dos profissionais da saúde.
\end{abstract}

Palavras-chave: Estresse; Fenomenologia existencial; Psicologia do trabalho.

\begin{abstract}
This article is the result of research conducted in the course of Specialization in Mental Health and Psychological Intervention, University of Maringá. The research aimed to investigate and comprehend, through interviews with employees of a health cooperative of the city of Maringa, how they mean and experience stress, as well as their actions on the same. It was used like a theoretical and methodological approaches, the phenomenology of Husserl and the phenomenological method; and Sartrian existentialism and the progressive-regressive method. The analysis showed that the stress is meant by workers in ahistorical, a-critical and individual. On one hand, they believe that external factors are responsible for the production of stress and, conversely, to take the blame for failing to overcome it. This understanding is corroborated by traditional hegemonic theories about stress and by the industry of health that do not alienate only the knowledge of employees on the subject, but also of health professionals.
\end{abstract}

Keywords: Stress; Existential phenomenology; Psychology of work.

Resumen: Este artículo es el resultado de la encuesta realizada en el curso de Especialización en Salud Mental e Intervención Psicológica de la Universidad de Maringá. La encuesta tuvo como objetivo investigar y comprender, partiendo de las entrevistas con los empleados de una cooperativa de salud de la ciudad de Maringá, cómo significan y cómo se experimenta el estrés, así como sus acciones sobre el mismo. Se utilizaron parámetros teóricos y metodológicos, la fenomenología de Husserl y el método fenomenológico, el existencialismo sartriano y el método progresivo-regresivo. El análisis señaló que el estrés es entendido por los trabajadores de forma no histórica, acrítica e individual. Ellos, por una parte, creen que los factores externos son responsables por la producción de estrés y, en forma contradictoria, asumen como propia la culpa por no superarlo. Este entendimiento, a su vez, es confirmado por las teorías hegemónicas tradicionales sobre el estrés y la industria de la salud, las cuales no solamente comprometen el conocimiento de los empleados sobre el tema, sino también el de los profesionales de la salud.

Palabras-clave: Estrés; Fenomenología existencial; Psicología del Trabajo.

"Nossa responsabilidade é muito maior do que poderíamos supor, porque ela engaja a humanidade inteira."

(Jean-Paul Sartre, 1946/1987)

\footnotetext{
Relato de pesquisa apresentado no II Congresso Sul Brasileiro de Fenomenologia - II Congresso de Estudos Fenomenológicos do Paraná: Vínculo, Diálogo e Relação, realizado na Universidade Federal do Paraná (UFPR), em Curitiba, de 02 a 04 de junho de 2011.
} 


\section{Introdução}

Segundo a Organização Mundial de Saúde, o estresse se tornou uma epidemia global. Nos Estados Unidos gastam-se de 50 a 75 bilhões de dólares por ano em despesas diretas e indiretas causadas pelo estresse. Dados do American Institute of Stress apontam que de todas as consultas a clínicos gerais nos Estados Unidos, 75\% a 90\% têm como causa distúrbios vinculados ao estresse, resultando em um gasto de US\$ 300 bilhões/ano. No Brasil, estima-se que os gastos cheguem a 3,5\% do PIB/ ano nacional (Rossi, Quick \& Perrewé, 2009).

Uma pesquisa realizada pela ISMA - BR (seção brasileira da International Stress Management Association) apontou que $70 \%$ dos brasileiros economicamente ativos sofrem tensão excessiva em seu cotidiano (Rossi, 2009). Segundo dados do IBGE (2009), até outubro de 2009 os trabalhadores com carteira assinada no setor privado (formal) somavam 9,5 milhões de pessoas e os empregados sem carteira (informais), cerca de 26 milhões, totalizando 35,5 milhões de trabalhadores, e, de acordo com informações do ISMA - BR, dentre estes, o número de estressados pode ser estimado em 24 milhões.

Modesto e Cardoso (2009) assinalam que atualmente o estresse vem ganhando importância, merecendo estudos e investimentos na prevenção. Nota-se um crescente aumento do número de pessoas em processo de estresse, devido, em grande parte, às particularidades da vida moderna, pois com a globalização vieram também a competitividade, o ritmo acelerado e o tempo escasso. O estresse tem sido considerado causa de problemas de ordem socioeconômica, por acometer todos os tipos de pessoas, independentemente de raça, sexo ou classe social.

Lipp (2004) explica que o estresse é um estado de tensão que causa uma ruptura no equilíbrio interno do organismo, e qualquer situação, boa ou ruim, que exija adaptação do organismo, é uma fonte de estresse. O estresse não é o causador de doenças graves, mas é o seu desencadeador, pois reduz a defesa imunológica do organismo e, conforme a vulnerabilidade da pessoa, podem aparecer doenças como infecções, úlceras, hipertensão, crises de pânico, ansiedade, herpes, alergias, psoríase, vitiligo, derrame, enfarte e outras.

No contexto do trabalho, para Pereira (2002), o desequilíbrio na saúde do trabalhador causado pelo estresse acarreta consequências negativas para as organizações, pois afeta a qualidade dos serviços prestados, aumenta o absenteísmo, o auxílio-doença, a reposição de funcionários, transferências, novas contratações e treinamentos. Devido a estes e outros fatores, "tem crescido a perspectiva de se investigar e se investir na qualidade de vida do trabalhador" (Pereira, 2002, p. 14).

Diante do crescente índice de pessoas acometidas pelo estresse, percebe-se que os estudos que mais tomam este tema como foco são os que se fundamentam na abordagem cognitivo-comportamental, os quais bus- cam prevenir e intervir com ações voltadas preferencialmente para o gerenciamento individual do estresse, por meio de mudanças cognitivas e comportamentais, e práticas de exercícios físicos e relaxamento (Freitas, 2009).

Em face deste cenário, observa-se certa escassez de produções que buscam compreender o fenômeno do estresse a partir do próprio indivíduo, não com o intuito de focar os sintomas pelos relatos de quem pode estar acometido pelo estresse, mas para compreender sua própria significação e a partir daí entender sua vivência.

Por meio de estudos e, mais especificamente, de trabalho com grupos de gerenciamento de estresse em uma cooperativa de saúde da cidade de Maringá/PR, foi possível observar que as formas de tratamento e prevenção baseadas no modelo cognitivo-comportamental apresentam resultados satisfatórios. Este modelo trabalha a reestruturação cognitiva, a aquisição de hábitos saudáveis, técnicas de relaxamento e respiração, além de outras questões fundamentais para uma vida saudável, porém não leva em consideração a pessoa enquanto ser que vivencia o estresse. Seus princípios são que cada um deve apreender uma verdade sobre o estresse instituída por outros, sem levar em conta as verdades dos próprios acometidos, a sua vivência, o significado desse processo para eles e o fato de que eles agem sobre o mundo de acordo com o sentido que dão ao estresse. Além disso, aquelas pessoas que não conseguem colocar em prática o que lhes é ensinado tendem a sentir-se frustradas, como se elas próprias fossem o problema, acarretando sentimentos de impotência, fracasso, gerando uma cultura de culpabilização, o que pode agravar o seu estado.

De acordo com Bocca e Freitas (2011), um fato se dá quando a verdade é dada e posta no mundo. Fato é o que as ciências empíricas consideram como realidade externa comum a todos os indivíduos. Por sua vez, o fenômeno é o modo como o indivíduo apreende o mundo, considerando a relação dialética entre indivíduo e mundo, entre idealismo e materialismo, bem como o modo como se dá a superação da contradição desta relação entre duas regiões ontológicas distintas, porém interdependentes.

Diante disso, como dito anteriormente, percebemos, através do trabalho realizado com esses grupos de gerenciamento de estresse baseado nas teorias hegemônicas sobre o assunto, que o estresse não era trabalhado como um fenômeno, por não considerar, no tratamento, o sentido dado pelo próprio indivíduo e, com isso, sua maneira de lidar com o estresse. O papel do psicólogo estava se resumindo em alguém que transmitia informações e ensinava técnicas para auxiliar o gerenciamento do estresse, ou seja, era algo mecânico e impessoal, e que coloca o psicólogo na condição de dono do saber.

Com isso, foi possível verificar que as técnicas utilizadas pelas teorias hegemônicas em relação ao tratamento e prevenção do estresse apresentam validade e importância, mas deixam lacunas no que diz respeito à pessoa en- 
quanto ser que significa e age em função do estresse que experiencia. Sendo assim, esta pesquisa se justificou pela necessidade de suprir esta lacuna e de ampliar as alternativas de trabalho sobre a temática do estresse, uma vez que se observou uma grande escassez em referenciais teóricos que abordem o tema com olhares diferenciados.

O presente estudo, então, direcionou o seu foco para os funcionários da cooperativa anteriormente mencionada, que lidam diretamente com o público (clientes da cooperativa), pois ocupações que exigem uma interação direta ou por telefone com os clientes são mais vulneráveis ao estresse, uma vez que envolvem trabalho emocional, ou seja, as emoções que os funcionários devem demonstrar seguem regras rígidas (Johnson et al., 2009). Segundo este mesmo autor, quando o trabalhador vivencia uma dissonância emocional no seu trabalho, pode haver sensações de hipocrisia, baixa autoestima e depressão.

Além disso, o enfoque nessa população justificou-se também por ser a que mais se mostrou interessada em participar dos grupos de gerenciamento de estresse realizados até o momento da pesquisa. Os trabalhadores que procuravam essa ajuda alegavam um nível de estresse muito elevado e apresentavam variadas justificativas, as quais acabavam não sendo consideradas pelo profissional que coordenava os grupos, devido à metodologia utilizada por exemplo, pontos importantes para o trabalho desenvolvido até então eram somente tomados como meio de os funcionários poderem participar dos grupos. Ademais, observou-se certa contradição na maneira como o trabalho vinha sendo conduzido, uma vez que, mesmo apresentando diversos motivos para o estresse vivido, todos se submetiam ao mesmo tipo de intervenção, devendo seguir uma lista de recomendações, tal como um receituário de como viver com qualidade.

Foi nesse contexto que surgiu, de uma maneira geral, a necessidade de investigar e compreender o fenômeno do estresse a partir dos próprios funcionários/colaboradores da cooperativa médica que lidam diretamente com o público. Mais especificamente: (1) conhecer e compreender como os funcionários compreendem, identificam e vivenciam o estresse, lidam com ele e buscam superá-lo e; (2) criar alternativas para a realização de intervenções com trabalhadores acometidos pelo estresse.

\section{Descrevendo os Caminhos Percorridos}

Metodologicamente, esta pesquisa se orientou pelo método fenomenológico de Husserl e pelo método progressivo-regressivo de Sartre. Através de uma atitude fenomenológica buscou-se compreender, a partir da própria pessoa que o experiencia, o fenômeno que se quer investigar; e pelo segundo, as escolhas realizadas pelos entrevistados, diante sua relação com o estresse. Sendo assim, o estresse, enquanto fenômeno, foi analisado a partir da perspectiva fenomenológico-existencial.
A população compreendeu colaboradores/funcionários de uma cooperativa de saúde da cidade de Maringá que trabalham diretamente com a clientela dessa cooperativa. No total somavam-se 70 (setenta) colaboradores, que trabalhavam distribuídos nos seguintes setores: central de atendimento ao cliente (call center - 35 colaboradores); pós-vendas (setor de reclamações - 7 colaboradores); atendimento e liberação de guias (22 colaboradores) e recepção das clínicas de Psicologia, Nutrição, Fisioterapia e Fonoaudiologia (6 colaboradores).

Quanto aos procedimentos, em um primeiro momento foi enviado aos 70 (setenta) colaboradores um questionário com perguntas específicas a fim de selecionar aqueles que seriam entrevistados. As perguntas do questionário inicial foram: (1) Você se considera uma pessoa estressada?; (2) Você conhece o trabalho realizado no Grupo de Gerenciamento de Estresse?; (3) Já participou deste grupo?; (4) Se sim, o que achou?; (5) Caso não tenha participado, deseja participar do grupo? Por quê?; (6) Caso já tenha participado, deseja participar de um novo grupo? Por quê? e; (7) Qual o horário que você considera ideal para poder participar do grupo?

A amostra para a entrevista foi, a princípio, definida em 10 (dez) colaboradores, independentemente do gênero, pois a pesquisa não objetivava este tipo de análise. A limitação da pesquisa a esse número de colaboradores deveu-se à saturação das respostas, pois ele foi o suficiente para a necessidade da pesquisa. Os dez trabalhadores foram selecionados de acordo com as respostas dadas ao questionário acima, seguindo o critério de seleção estabelecido de acordo com a ordem a seguir: $1^{0}$ - colaboradores que afirmavam estar estressados, nunca haver participado dos grupos de gerenciamento de estresse e ter o desejo de participar; $2^{\circ}$ - colaboradores que afirmavam estar estressados, nunca haver participado nem desejar participar dos grupos de gerenciamento de estresse e; $3^{\circ}$ - colaboradores que afirmavam estar estressados, já haver participado dos grupos de gerenciamento de estresse e ter o desejo de participar de novo.

Este critério de seleção foi estabelecido no intuito de compor uma amostra formada de colaboradores que tivessem dado ao estresse um sentido menos contaminado pelas informações passadas durante o trabalho realizado com os grupos de gerenciamento de estresse. É importante ressaltar que os dez colaboradores selecionados estavam dentro do primeiro critério.

Após a seleção da amostra, conforme descrito anteriormente, foram utilizadas entrevistas abertas com os 10 (dez) colaboradores selecionados, as quais foram gravadas com a permissão dos entrevistados mediante a assinatura de um termo de consentimento livre e esclarecido. Em consonância com os objetivos específicos, as entrevistas foram dirigidas pelas seguintes questões norteadoras do diálogo entre a pesquisadora e os (as) entrevistados (as): (1) O que é o estresse para você?; (2) Como você identifica quando está estressado (a)?; (3) Em que época você começou a perceber 
que estava estressado (a)?; (4) A quem e/ou a quê você atribui a responsabilidade pelo seu estresse?; (5) Como você vivencia o estresse? e; (6) Como você busca superar o estresse?

Depois de realizada, individualmente, a entrevista com os funcionários selecionados, as repostas foram transcritas e os fenômenos encontrados nas falas dos entrevistados, para cada questão, foram agrupados dentro de unidades de sentido relacionadas a cada uma das categorias a seguir: (1) O significado do estresse; (2) Como o estresse é identificado; (3) Ponto temporal do início da percepção de que estava estressado; (4) Causas/motivos do estresse; (5) Como o estresse é vivenciado; (6) Maneiras de superar o estresse.

Para identificar os fenômenos nas falas dos entrevistados, após a transcrição integral das entrevistas foi utilizada a redução fenomenológica, conforme a proposta de Forghieri (1993) para a entrevista fenomenológica. Assim, inicialmente foi lançado um olhar ingênuo sobre a experiência investigada, e em seguida, realizada a redução fenomenológica a partir de dois momentos: o envolvimento existencial e o distanciamento reflexivo. No primeiro momento o intuito foi sair de uma atitude intelectualizada e se permitir penetrar na vivência do sujeito de forma espontânea e profunda, deixando surgir a intuição, a percepção, sentimentos e sensações, com vista a proporcionar uma compreensão global, intuitiva e pré-reflexiva desta vivência. No segundo momento, denominado de distanciamento reflexivo, a pesquisadora estabeleceu certo distanciamento da vivência por meio das falas dos entrevistados, para, a partir destas, refletir sobre essa compreensão e tentar captar e descrever o significado daquela vivência naquela existência.

Depois de os sentidos dados pelos entrevistados a cada questão norteadora terem sido conhecidos e alocados nas respectivas categorias, foi possível realizar a análise crítica dos resultados com fundamento nos conceitos existencialistas sartrianos.

Foi tomado como base o modo como os entrevistados significavam e identificavam o estresse, em que época haviam começado a perceber que estavam estressados, a quem e/ou a quê atribuíam a responsabilidade pelo seu estresse, como este era vivenciado por eles e as maneiras como buscavam superar o estresse.

Como o estresse é também produzido pela sociabilidade e pelas normas impostas pelo social e nestas se incluem as questões relacionadas ao trabalho, não podemos partir do entendimento de que o estresse fundamenta-se apenas no indivíduo, sem considerar suas relações com o mundo, uma vez que esse homem é um homem em situação. Assim foi possível compreender a vivência do estresse pelo trabalhador e o modo como este age sobre o mundo a partir desta vivência, a qual pode alterar ou não o mundo posto.

Também a partir dessa análise foi possível conhecer o que ainda pode ser implementado nos programas de gerenciamento de estresse para uma maior efetividade dos resultados.

\section{Compreendendo o Estresse a partir dos Trabalha- dores}

No que se refere à categoria 1 - O significado do estresse, foi possível observar que todos os entrevistados o compreendem como fato isolado, ou seja, associam-no a eventos e/ou situações desconectados de um contexto maior, e acabam significando o estresse ou como desencadeador de sintomas e/ou como o sintoma em si.

Observando as respostas dadas no que se refere à $c a$ tegoria 2 - Como o estresse é identificado e à categoria 3 - Ponto temporal do início da percepção de que estava estressado, percebe-se que as unidades de sentido identificadas em ambas corroboram o observado na Categoria 1 , a qual compreende os significados dados ao estresse.

A questão da temporalidade numa concepção linear de causa/efeito é observada nestas duas categorias (2 e 3). Na categoria 2 foi observado que o estresse é compreendido somente como produtor de sintomas, uma vez que, ao responderem à questão referente ao modo como identificam o estresse, os entrevistados mostram que o fazem por meio de sintomas já instaurados ou de comportamentos consequentes deste.

$\mathrm{Na}$ Categoria 3, os entrevistados afirmam que o estresse começou após a ocorrência de algum evento isolado em suas vidas; ou seja, nessa categoria o estresse surge, para eles, como consequência, como produto.

Nas três categorias anteriores se pôde observar que os sentidos do estresse se entrelaçam, dando coerência à maneira de compreender como os entrevistados o significam. A significação dada ao estresse, que ora foi apresentado como causa, ora como consequência, pode ser compreendida pelo fato de os entrevistados, ao significarem o estresse, fundamentarem suas definições ou em eventos isolados em suas vidas (que para eles seriam as causas do estresse) ou nos sintomas (neste caso, consequência da doença).

Com isso se nota um entendimento em que os entrevistados não se percebem numa relação cúmplice com a produção do estresse. Passivamente, se sabem como vítimas, ora expostos a situações externas e isoladas, geradoras do estresse, ora acometidos por sintomas decorrentes desse. Nota-se em falas dos entrevistados como, por exemplo, "Estresse acho que é assim, a rotina de trabalho [...]"; "[...] é estar sobrecarregada [...]"; "Seria uma pressão psicológica em todos os sentidos [...]".

Sartre (1943/2007) coloca que o indivíduo tem uma relação de interdependência com o mundo, em que a existência e o mundo são construídos a cada ato humano, atos que requerem escolhas que vão transcender ou manter o que já foi construído por ele mesmo e pelos outros, como coisas ou valores, normas, regras, por exemplo, mas nossos entrevistados se negam no processo dialético da construção do estresse.

A partir disso podemos inferir que o conhecimento desses trabalhadores apóia-se nas teorias tradicionais, as quais explicam que o estresse pode advir de algum evento de 
fora do organismo, como, por exemplo, a perda de emprego, separação conjugal, excesso de compromissos, dentre outros, bem como, de algo interno, dependendo das crenças, valores e forma de pensar de cada um, como, por exemplo, excesso de preocupação, coisas que afligem, etc.

Segundo essas teorias tradicionais, eventos estressores ocorrem na vida de qualquer pessoa e existe uma maneira correta de fazer o enfrentamento ou gerenciamento, a qual, de acordo com pesquisas, ameniza os efeitos do estresse. Na observância dessa maneira de tratar o estresse são tomadas medidas paliativas que levam ao restabelecimento do equilíbrio do organismo, as quais seguem uma ordem de disciplina e cuidado com o corpo e a mente. Neste sentido, o estresse é visto como uma espécie de doença, da qual o homem pode se curar seguindo os conhecimentos produzidos por profissionais e/ou teóricos da saúde.

Não obstante, o problema central da relação deste homem com o mundo, cuja práxis configura sua existência, permanece intacto, pois essas teorias contribuem para uma visão de mundo naturalizada, reducionista, a-histórica, acrítica, acentuando a idéia de indivíduo desconectado do coletivo e do mundo das coisas. Dessa forma elas concorrem para a manutenção da alienação e passividade no que diz respeito ao mundo já posto, ajudando a perpetuar as histórias do estresse construídas até o momento, o que demonstra um retrocesso na compreensão da condição humana.

Somente na relação com o mundo acontece a “(...) interiorização do exterior e exteriorização do interior, na construção da subjetivação objetivada e da objetivação subjetivada" (Bocca \& Freitas, 2011) e consequente mudança da realidade objetiva para algo próximo da autenticidade do indivíduo, qual seja, sua humanidade.

Observando as respostas dadas no que se refere à $c a-$ tegoria 4-Causas/motivos do estresse, reincide a percepção dicotomizada entre os entrevistados e o mundo, haja vista, que atribuem a causa do estresse a condições que, através de uma consciência cúmplice, não são justificadas em suas escolhas, tais como suas condições históricas, biológicas e/ou psicológicas.

No que diz respeito à categoria 5 - Como o estresse é vivenciado, como mostrado na categoria anterior, a maioria não se percebe responsável pelo estresse, o que concorre para vivências emocionais desgastantes, sendo que a maioria dos entrevistados também atribui, contraditoriamente, somente a si próprios a responsabilidade pela superação deste estado, potencializando assim, a vivência de impotência diante o fenômeno.

Coerente com a cristalização dos antagonismos que permeiam o fenômeno do estresse, o que dificulta saídas que possam superá-lo, na categoria 6-Maneiras de superar o estresse, foi observado que todos os entrevistados buscam medidas paliativas para a superação do estresse, que visam atacar os sintomas e não a maneira pela qual o estresse é produzido.
Nota-se que a concepção reducionista, a-histórica e acrítica dos entrevistados sobre o sentido e a identificação do estresse e o modo como perceberam seu início persiste quando eles são questionados sobre os motivos/causas do estresse e como eles o vivenciam. Em suas respostas se observa, num nível mais acentuado, a presença de preconceitos construídos por paradigmas que constituíram o indivíduo dissociado do coletivo.

Ao definirem-se si próprios como a única fonte de responsabilidade pelo estresse, sugerindo a autoculpabilização por não conseguirem evitar ou curar-se deste mal, denotam um conceito conforme com as teorias tradicionais hegemônicas, as quais ensinam ao indivíduo como lidar com o estresse, mas não o ajudam a compreender sua construção, nem a refletir sobre a maneira como o compreende.

Ensinamentos dados a um indivíduo que se compreende desconectado do mundo podem contribuir para a manutenção do estresse ou seu aumento, se a esse indivíduo são omitidos seus interlocutores na construção desse mal: o mundo e neste, os outros.

Foi possível observar as maneiras individualizadas de transcendências nas falas seguintes: "Acho que espero passar, eu sei que vai passar [...]”; “[...] adoro fazer coisas manuais, adoro participar das atividades dos meus filhos [...] me relaxam"; "[...] tentar ler alguma coisa, assistir alguma coisa na TV, filme [...]"; "Atividade física, isso me ajuda bastante [...]”; "[...] às vezes eu saio de casa, escuto uma música, me relaxa bastante”.

As medidas que esses entrevistados tomam para superar o estresse são justamente as que as teorias tradicionais recomendam, porém elas não conseguem resultado efetivo. É comum lermos matérias de jornais e revistas sobre o assunto que apontam para a questão de hábitos saudáveis como medidas preventivas do estresse, como, por exemplo, maior duração e qualidade de sono, alimentação saudável, exercícios físicos, lazer, uso de técnicas de relaxamento e de terapias alternativas. Além disso, dependendo de como a pessoa encara a vida, torna-se necessário mudar o padrão de comportamento e encarar os fatos de uma forma diferente, mais positiva.

Produções científicas como as de Lipp (2004), fornecem recomendações as quais o tratamento do estresse se baseia em quatro pilares: alimentação, relaxamento, exercícios físicos e reestruturação de aspectos emocionais. Este último consiste em conhecer a si mesmo e mudar o modo estressante de pensar, sentir e agir. Dessa forma, observa-se que a responsabilidade é delegada a um individuo descontextualizado da história, do social.

Nas teorias tradicionais hegemônicas sobre estresse nota-se uma visão determinista; mas o homem não está determinado no seu vir-a-ser como os outros animais, ou seja, está por se fazer, é um projeto não determinado e será "(...) aquilo que fizer com aquilo que se fez dele" (Maheirie \& Pretto, 2007, p. 457). Se não há determinismo na construção de uma existência estressada, também 
pode ser falho pensar num determinismo para sua superação. As possibilidades para Sartre (1960/2002) podem ser determinadas pelo indivíduo quando o que projeta no futuro contrasta com o estado atual em que se encontra, ou considerar ao contrário, que será o estado das coisas que definirá a necessidade de mudança. Concordamos com este autor quando coloca que é o projeto futuro que determinará se uma situação atual deve ou não ser superada, assim não será a condição de estresse que definirá a sua transcendência, tão pouco os modelos ensinados para com ele se lidar. A busca efetiva pela sua superação ou não, somente se dará se o indivíduo posicionar uma maneira diferente de lidar com as ambiguidades que permeiam sua realidade.

Sendo assim, pode-se dizer que o homem tem condições de refletir e se posicionar sobre suas escolhas e seu modo de agir para, a partir disso, eleger e assumir seu projeto rumo à humanização. Para isso, é fundamental se perceber como um ser livre e relacionado com um mundo objetivo, numa relação dialética de exteriorização do interior e interiorização do exterior.

Se muito da influência do estresse pode estar relacionado às resistências que os indivíduos encontram no mundo, paradoxalmente, essas resistências são necessárias à nossa liberdade, uma vez que para sermos livres precisamos agir sobre o mundo, e para isso, somente terá sentido o exercício de nossa liberdade diante de algo que nos opõe resistência. Tomar somente o biológico e o psicológico como fontes do estresse a serem atacadas é incitar a uma luta contra nós mesmos, na qual ganhamos ou perdemos sozinhos, e assim desconsideramos um mundo e o outro, que tanto nos podem opor resistências como servirnos de aliados no combate aos obstáculos. Em outras palavras, direcionar o tratamento do estresse somente para 0 ataque aos sintomas é o mesmo que não entender que o estresse pode ser construído na relação homem-mundo. Com isso se perde a oportunidade de comungar com outras pessoas projetos em comum e unir liberdades para superar as resistências que provocam estresse.

Destarte, nota-se que o ponto central está na relação dialética de um homem histórico e social, concepção que é negada pelos entrevistados e pelas teorias hegemônicas sobre estresse.

Conceitos conformes com as teorias que trazem uma visão naturalizante e não crítica contribuem com o círculo de perversidade no qual o homem está inserido e que ele ajuda a construir, pois a visão dicotomizada da relação entre o homem e o mundo coloca o primeiro em um mundo já posto e acabado, sem que ele tenha a possibilidades de criar suas próprias saídas, e assim contribuem também com a construção da cultura da culpa, uma vez que o indivíduo pode não conseguir superar sozinho o seu processo de estresse, desconsiderando que na construção deste há influências da história e do social. Exigir isto do indivíduo seria impor uma luta solitária consigo próprio, tal como uma proposta que mostra um acovarda- mento diante a responsabilidade social pelas condições de existência coletiva produzida. Diante disso não se poderia falar de liberdade, condição ontológica do homem, haja vista que, como disse Sartre (1943/2007), ser livre é escolher dentre os possíveis.

\section{Estresse em prol da Indústria da Saúde}

E por falar de atitudes que negam a responsabilidade por suas práxis, paradoxalmente, a subjetivação da culpa produzida pelas teorias hegemônicas do estresse depende proporcionalmente da maneira como os indivíduos escolhem afirma-la como verdade. A ratificação do entendimento de que o estresse é de responsabilidade somente do indivíduo, tanto do acometimento quanto da superação, contribui sobremaneira com a indústria da saúde. Discursos que buscam prevenir ou combater o estresse que versam sobre a alimentação, práticas de relaxamento, exercícios físicos, reestruturação de aspectos emocionais, terapias alternativas, além de tratamentos médicos e medicação, no caso de necessidade, podem ser eficazes para combater sintomas isolados e individuais, mas ignoram todos os cenários produtores do estresse.

Não podemos ser ingênuos a ponto de ignorar que o fenômeno do estresse beneficia a muitos que com ele desejam obter lucros; por detrás desta ideologia que prega o bem-estar e a felicidade está uma classe hegemônica que explora a relação entre produção e consumo, oferecendo serviços e bens médico-assistenciais e estimulando um consumo cada vez mais intensivo desses bens (Barros, 2002).

Esse consumismo apregoado na sociedade atual, especificamente na indústria da saúde, faz com que esta se transforme em mercadoria para produzir lucros (Barros, 2002). É preciso haver consumidores, e a felicidade e bemestar parecem ser um grande negócio, já que constituem uma condição almejada por todos. O estresse atualmente é encarado como o mal do século, por isso todos os dias surgem serviços voltados a seu tratamento e prevenção. São oferecidos serviços como tratamentos alternativos e específicos, medicamentos e até mesmo as terapias que promovem a adaptação/modificação do padrão de comportamento para uma vida mais satisfatória. Por sua vez, as teorias hegemônicas promovem este consumo, uma vez que rotulam o indivíduo como único responsável pelo estresse e sua cura.

Segundo Freitas (2009), vivemos em um momento sócio-histórico em que as práxis capitalistas buscam o controle da liberdade do homem, fazendo-o realizar, de forma alienada, projetos que não são seus e direcionando esses projetos ao contexto da produção e do consumo. Com isso são instituídos "(...) padrões de condutas que buscam destituir do indivíduo sua condição humana de ser livre, que incita as relações de poder com mecanismos, muitas vezes obscuros, de controle da liberdade" (Freitas, 2009, p. 165). 
Sobre esta situação podemos mencionar novamente Sartre (1960/2002) sobre as determinações das possibilidades. A amplitude de pessoas que se percebem estressadas criou, no interior da própria situação, uma perspectiva futura: a da cura do estresse. Tal necessidade é assim desvelada pelo mercado de consumo ao vislumbrarem saídas que lhe geram lucros. Aliado a compreensão individualizante na maneira de se lidar com o estresse, emerge e se mantém a indústria da saúde.

Percebe-se também que os colaboradores entrevistados, além de estarem alienados de seu processo de estresse e da forma de tratá-lo, também sugerem estar alienados de seu próprio trabalho, pois não projetam o seu trabalho a partir de suas necessidades, mas a partir das de outros. Tanto no âmbito privado quanto no público, os projetos institucionais e organizacionais tendem a ser escolhidos por alguns que precisam de outros para que sejam atingidos (Freitas, 2009).

Dessa maneira, o trabalhador não vê o seu trabalho como um meio de obter um fim de um projeto seu, a completude de uma carência, mas se perde no seu projeto ao acatar o projeto de outros, contribuindo para manter o status quo da sociedade capitalista, sustentado pela díade produção e consumo. A maneira alienada de trabalho influi na produção e manutenção do estresse, afetando a motivação e disposição do indivíduo, já que este não se reconhece na matéria trabalhada, logo o sentido para o seu trabalho. Realizando o projeto de outrem, o produto final de seu trabalho não é reconhecido como seu.

Pelo exposto se observa que a classe hegemônica impõe suas verdades, necessidades e desejos, de modo que muitos trabalhadores, ao aceitarem o que lhes é imposto, não percebem que na realidade suas escolhas irão concretizar projetos alheios. E sentem-se livres somente para usufruir dos bens de consumo da área da saúde para lidarem com as adversidades da vida que provocam o estresse, conforme destacam as teorias hegemônicas sobre o assunto.

São inúmeros os envolvidos no tratamento e prevenção do estresse, cada um com suas medidas, por vezes também alienantes, que geralmente tratam o sujeito de maneira individualizada e descontextualizada, desconsiderando o fundamental: a relação dialética entre homem e mundo; assim, mantêm o trabalhador alienado de suas possibilidades.

Essa passividade é interessante para o sistema vigente, pois ao mesmo tempo em que faz o homem permanecer em um processo de adoecimento (por meio da alienação de seu trabalho, do processo e cura do estresse), faz com que ele usufrua dos bens ofertados pela indústria da saúde, já que é considerado o único responsável pelo tratamento do seu estresse. Uma vez alienado conforme essas verdades com as quais também compactua, o homem continuará usufruindo constantemente das vendas de serviços, pois, à medida que não se percebe livre, estará envolvido em um constante círculo vicioso da máxima capitalista de produzir para consumir. Essa perversidade na qual o homem está inserido e que é também responsável pela sua manutenção fá-lo perceber-se em um mundo objetivado, sem possibilidades de mudança, restando-lhe apenas as medidas oferecidas pelas teorias tradicionais hegemônicas para o tratamento do estresse, já que para conhecer esta realidade, é necessário ter consciência de como a conhece, o que implica em um processo de reflexão crítica.

Sartre (1943/2007) aponta que o indivíduo tem com o mundo uma relação de interdependência, de modo que existência e mundo são construídos a cada ato humano; por sua vez, esses atos requerem escolhas que vão transcender ou manter o que já foi construído por ele mesmo e pelos outros. Não obstante, a única saída que os entrevistados mencionaram para prevenir ou tratar o estresse é lutar sozinho para transcender um coletivo. Isso ele faz consumindo o que a indústria da saúde oferece, e o fundamento ele encontra nas teorias tradicionais hegemônicas existentes. Assim, a práxis do homem atual observada nas entrevistas, no que se refere ao estresse, contribui para a manutenção do que já está construído sobre esse mal: uma vivência de culpabilização do indivíduo e o enriquecimento da indústria da saúde.

\section{Considerações Finais: Transcendendo a Própria Alienação}

Por meio desta pesquisa pudemos perceber a importância de se compreender o estresse como um estado construído na relação homem-mundo, de forma que não se pode culpabilizar nem o indivíduo nem o coletivo separadamente, uma vez que o resultado desta relação é de responsabilidade de todos; contudo, por esta compreensão só pudemos fazer escolhas em função das reflexões realizadas a partir desta pesquisa.

Com o desenrolar desta pesquisa, observamos o quanto muitas práticas de profissionais da Psicologia contribuem para manter uma compreensão dicotomizada do fenômeno do estresse, além de colocar o psicólogo como dono de um saber instituído. Esta conscientização gera também preocupação sobre como modificar a realidade objetiva referente ao estresse, uma vez que a possibilidade de se modificar esta situação será através de um projeto que vise alternativas diferentes dos paradigmas existentes, ou seja, que conceba a relação do homem com o mundo de maneira dialética.

Podemos dizer que continuar compreendendo o estresse como uma condição natural e a-histórica, numa perspectiva reducionista e sem uma consciência reflexiva crítica, fará com que a responsabilidade continue recaindo somente sobre o indivíduo e/ou o profissional da saúde que assim também compreende essa questão, e não sobre a construção da relação, o que contribuirá para a manutenção da alienação e da passividade e para a perpetuação das percepções sobre o estresse até então aceitas. 
Este novo modo de compreender o estresse denota a importância desta pesquisa, uma vez que o estresse deve ser encarado como práxis e essa práxis atual é resultado da história de outros homens e de suas relações com o mundo. Ela só pode ser mudada por meio da conscientização e compreensão de que o homem é uma totalizaçãoem-curso, ou seja, com a noção de projeto e seus possíveis. Por outro lado, cumpre levar em conta que essa mudança não será fácil, tendo-se em vista quanto a maneira de tratar o estresse atualmente vai ao encontro dos interesses da indústria da saúde, das organizações e instituições hegemônicas, que, para livrar-se da responsabilidade como produtores também do estresse, apontam a luz somente para o indivíduo, ação de má-fé ratificada por muitas das teorias hegemônicas existentes sobre a temática.

Enfim, conforme já colocado, é fundamental encarar o estresse como produto da relação indivíduo/coletivo. Com relação ao trabalho com os grupos de gerenciamento de estresse, entendemos que as práticas empregadas para trabalhar esta temática não devem ser totalmente descartadas, mas complementadas com os dados obtidos por meio desta pesquisa, para assim fechar a lacuna anteriormente citada. Vemos a necessidade de, antes de qualquer coisa, realizar um trabalho que promova a reflexão dos e entre os funcionários, objetivando incitá-los à novas maneiras de compreender o respectivo fenômeno.

Além disso, é preciso também ajudar os trabalhadores a se conscientizarem sobre seus projetos, para que eles possam escolher, de maneira responsável, projetos possíveis de se realizar, pois conforme Sartre (1943/2007), ser livre é escolher saídas possíveis. Isso poderá ser feito desvelando-se e superando-se os preconceitos das verdades ratificadoras do prático-inerte eleito pelos trabalhadores e ajudando-os a modificar sua maneira de viver (Freitas, 2009).

Esta reflexão não bastará para superar este mal, pois o mundo opõe resistências a essa superação; mas cada indivíduo, numa reflexão individual, poderá construir coletivamente melhores saídas. Desta maneira, poderá ser possível romper com o círculo vicioso e com algumas práxis cristalizadas, quiçá construindo um trabalho mais humanizado com esses grupos, focos de nossa pesquisa.

\section{Referências}

Barros, J. A. C. (2002). Pensando o processo saúde doença: a que responde o modelo biomédico? Saúde \& Sociedade, 11 (1), 67-84.

Bocca, M. C. \& Freitas, S. M. P. (2011). O eu está no mundo! A Psicoterapia Existencialista como uma das vias para a consciência do eu. Em M. C. Laurindo (Org.), Teorias Psicológicas: a subjetividade abordada em seus vários enfoques (93-118). Curitiba: Champagnat.

Forghieri, Y. C. (1993). Psicologia fenomenológica: fundamentos, métodos e pesquisa. São Paulo: Pioneira.
Freitas, S. M. P. (2009). O psicólogo do trabalho no mundo das práxis capitalista: reflexões fenomenológico-existenciais. Revista da Abordagem Gestáltica, 15 (2), 157-168.

Johnson, S., Cooper, C. L., Cartwright, S., Donald, I., Taylor, P., \& Millet C. (2009). A vivência do stress relacionado ao trabalho em diferentes ocupações. Em A. M. Rossi, C. Quick, \& P. L. Perrewé (Orgs.), Stress e qualidade de vida no trabalho: o positivo e o negativo (65-77). São Paulo: Atlas.

Lipp, M. E. N. (2004). O stress está dentro de você. São Paulo: Contexto.

Maheirie, K. \& Pretto, Z. (2007, julho/dezembro). O movimento Progressivo-Regressivo na dialética universal e singular. Revista do Departamento de Psicologia - UFF, 19 (2), 455-462.

Modesto, M. M. L. \& Cardoso, O. O. (2009). Relações cotidianas na síndrome de Burnout em profissionais de enfermagem. Anais do $9^{\circ}$ Congresso de Stress da ISMA-BR e $11^{\circ}$ Fórum Internacional de Qualidade de Vida no Trabalho. Porto Alegre, RS, Brasil.

Perdigão, P. (1995). Existência e liberdade: uma introdução à Filosofia de Sartre. Porto Alegre: L\&PM.

Pereira, A. M. B. (2002). Burnout: quando o trabalho ameaça o bem-estar do trabalhador. São Paulo: Casa do Psicólogo.

Rossi, A. M., Quick, C., \& Perrewé, P. L. (Orgs.) (2009). Stress e qualidade de vida no trabalho: o positivo e o negativo. São Paulo: Atlas.

Sartre, J. P. (1987). O existencialismo é um humanismo. São Paulo: Nova Cultural (Original publicado em 1946).

Sartre, J. P. (2002). Crítica da razão dialética. Rio de Janeiro: DP\&A (Original publicado em 1960).

Sartre, J. P. (2007). O ser e o nada: ensaio de ontologia fenomenológica. Petrópolis: Vozes (Original publicado em 1943).

Melck Kelly Piastrelli Mota da Silva - Especialista em Saúde Mental e Intervenção Psicológica pela Universidade Estadual de Maringá (UEM), Gestalt-terapeuta pelo Instituto Maringaense de Gestaltterapia. Atua como Psicóloga do setor de medicina preventiva de uma cooperativa de saúde.E-mail: melckkelly@yahoo.com.br

Sylvia Mara Pires de Freitas - Psicóloga. Mestre em Psicologia Social e da Personalidade pela Pontifícia Universidade Católica do Rio Grande do Sul (PUC/RS), e Docente dos cursos de Psicologia da Universidade Estadual de Maringá (UEM) e da Universidade Paranaense (UNIPAR/Umuarama/PR). Endereço Institucional: Universidade Estadual de Maringá, Centro de Ciências Humanas Letras e Artes, Departamento de Psicologia. Avenida Colombo, 5790 - Campus Universitário (Jardim Universitário). CEP 87020-270. Maringá/PR. E-mail: sylviamara@gmail.com

Recebido em 02.06.11 Aceito em 12.12.11 